\title{
Estresse salino na emergência e desenvolvimento inicial de plântulas de jurema-branca
}

\author{
Narjara Walessa Nogueira ${ }^{1}$ Rômulo Magno Oliveira de Freitas ${ }^{2}$ Caio César Pereira leal ${ }^{1 *}$ Salvador \\ Barros Torres ${ }^{1}$
}

${ }^{1}$ Universidade Federal Rural do Semi-árido, Av. Francisco Mota, 572, Costa e Silva, CEP 59625-900, Mossoró, RN, Brasil

${ }^{2}$ Instituto Federal de Educação, Ciência e Tecnologia do Rio grande do Norte, BR- 405, S/N, Chico Cajá, CEP 59000-900, Pau dos ferros, RN, Brasil

\section{Artigo original \\ *Autor correspondente: caioleal3@hotmail.com \\ Keywords: \\ Piptadenia Stipulacea \\ Irrigation \\ Salinity \\ Vigor}

Palavras-chave:

Piptadenia Stipulacea

Irrigação

Salinidade

Vigor

Recebido em

2019/07/11

Aceito em

2020/06/22

Publicado em

2020/11/02

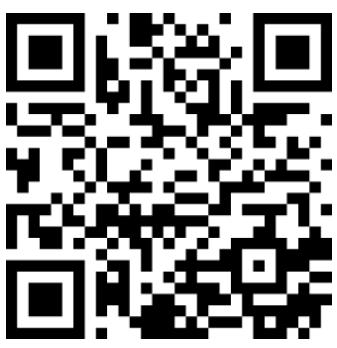

DOI: http://dx.doi.org/ 10.34062/afs.v7i3.8624

\section{(cc) BY}

RESUMO: Piptadenia stipulacea Benth., conhecida popularmente como jurema-branca, é uma espécie arbórea de pequeno porte, nativa da Caatinga, amplamente distribuída na região Nordeste do Brasil, sendo considerada de grande interesse comercial, econômico e ambiental para a região pelas suas características de uso múltiplo. O presente trabalho teve como objetivo avaliar o efeito de diferentes concentrações salinas em água de irrigação na emergência e desenvolvimento inicial de plântulas de jurema-branca. O delineamento estatístico utilizado foi o inteiramente casualizado, com sete tratamentos e quatro repetições, com 25 sementes cada. Os tratamentos consistiram das concentrações salinas $(0,5$; 1,$5 ; 2,5 ; 3,5 ; 4,5 ; 5,5$ e $\left.6,5 \mathrm{dS} \mathrm{m}^{-1}\right)$, que foram obtidas através da adição de $\mathrm{NaCl}$ em água, de forma que as soluções fossem calibradas para as condutividades elétricas pré-estabelecidas. As variáveis avaliadas foram a porcentagem de emergência, e velocidade de emergência, altura de plântula, número de folhas, comprimento de raiz e massa seca da parte aérea, raiz e total. Foram verificadas reduções nas variáveis estudadas, com exceção do comprimento de raiz. A espécie possui tolerância moderada a salinidade, suportando salinidades de $4,5 \mathrm{dS} \mathrm{m}{ }^{-1} \mathrm{sem}$ que haja perdas significativas de germinação e número de folhas. No entanto, a irrigação com água salina afeta de forma negativa as plântulas de jurema-branca, comprometendo seu desenvolvimento quanto ao acúmulo de massa e crescimento da parte aérea.

\section{Salt stress in emergency and initial development in "jurema-branca" seedling}

\begin{abstract}
The Piptadenia stipulacea Benth., popularly known as juremabranca, is an small arboreal species, native of Caatinga, widely distributed in northeastern Brazil, being considered of great commercial, economic and environmental interests in the region due to its characteristics of multiple use. This study aimed to evaluate the effect of different salt concentrations in irrigation water in the emergence and initial development in jurema-branca seedling. The statistical design was completely randomized design with seven treatments and four replicates with 25 seeds each. The treatments consisted of salt concentrations $\left(0.5 ; 1.5 ; 2.5 ; 3.5 ; 4.5 ; 5.5\right.$ e $\left.6.5 \mathrm{dS} \mathrm{m}^{-1}\right)$, which were obtained by addition of $\mathrm{NaCl}$ in water so that the solutions were calibrated to the pre-established electrical conductivities. The variables were: Percentage of emergency, rate of emergence, seedling height, number of leaves, root length and shoot, root and full dry mass. Reductions were observed in the studied variables, with the exception of the root length. The species has moderate tolerance to salinity, tolerating salinities of 4.5 $\mathrm{dSm}^{-1}$ without significant loss of germination and number of leaves. However, irrigation with saline water affects negatively the jurema-branca seedlings, compromising their development with regard to mass accumulation and shoot growth.
\end{abstract}




\section{Introdução}

A Piptadenia stipulacea Benth. (Fabaceae), é uma espécie arbórea de pequeno porte, nativa da Caatinga, amplamente distribuída na região Nordeste do Brasil e considerada de grande interesse comercial, econômico e ambiental para a região pelas suas características de uso múltiplo. Conhecida popularmente como jurema-branca, é utilizada na marcenaria, construção civil, na produção de estacas, lenha, carvão, também sendo usada na medicina popular em tratamentos de queimaduras e problemas de pele, antimicrobiano, analgésico, regenerador de células, antitérmico e adstringente peitoral (Maia, 2012).

$\mathrm{Na}$ restauração florestal e nos sistemas agroflorestais, a $P$. stipulacea tem papel importante na recuperação de solos, uma vez que é capaz de fixar nitrogênio, por meio de simbiose com certas bactérias, sendo indicada para a recomposição florestal mista de áreas degradadas, bem como fornecer pólen e néctar para as abelhas e servir de forragem para caprinos e ovinos (Maia, 2012). No entanto, os programas de reflorestamento demandam grandes quantidades de produção de mudas, tornando-se necessário conhecer os fatores que limitam o desenvolvimento da espécie, como a salinidade e sodicidade, condições frequentemente constatadas em solos tropicais.

Em solos de regiões tropicais, a água subterrânea é a principal fonte de suprimento hídrico para as espécies florestais, e está sujeita à salinização frequente causada pela alta força evaporativa do ar, que provoca à saída de água da superfície do solo, tornando-o mais salinizado do que nas camadas mais profundas. Sais contendo sódio, cálcio e magnésio são os mais comuns, e os elevados níveis de salinização afetam o potencial hídrico do solo, $\mathrm{pH}$ e a atividade microbiana (Perez e Jardim, 2005).

Prejuízos no processo fisiológico, devido ao baixo potencial osmótico proporcionado pelas condições de salinidade, são devidos à influência na viabilidade e vigor, observados principalmente em sementes de espécies mais suscetíveis a salinidade, classificadas como glicófitas (Holanda et al. 2010).

Vários estudos têm sido realizados demonstrando os efeitos prejudiciais do aumento dos níveis de salinidade da água de irrigação no desenvolvimento de espécies florestais, como os de Andréo-Souza et al. (2010) com Jatropha curcas, Freitas et al. (2010) com Caesalpinea férrea Mart., Barreto et al. (2010), Nogueira et al. (2012a) com Delonix regia L. Guimarães et al., (2013) com Erythrina velutina Willd., Leal et al. (2015) com Mimosa ophthalmocentra Mart. Ex Benth., Matias et al. (2018) com Cenostigma pyramidale (Tul.) Gagnon \& G.P.Lewis, e Leal et al. (2019) com Combretum leprosum Mart., no entanto são escassos trabalhos desse tipo com P. stipulacea. Dessa forma, objetivou-se com este trabalho avaliar o efeito de diferentes concentrações salinas em água de irrigação na emergência e desenvolvimento inicial de plântulas de $P$. stipulacea.

\section{Material e Métodos}

O experimento foi realizado em casa de vegetação do Departamento de Ciências Vegetais da Universidade Federal Rural do Semi-Árido UFERSA, Mossoró - RN. Para isso, frutos (vagens) maduros e secos foram coletados de 10 plantas matrizes situadas na comunidade Maísa, Mossoró, $\mathrm{RN}$ ( $5^{\circ} 11^{\prime} \mathrm{S}, 37^{\circ} 20^{\prime} \mathrm{W}$ e $18 \mathrm{~m}$ de altitude). As sementes foram extraídas das vagens, beneficiadas manualmente e colocadas para secar à sombra. Em seguida, foram acondicionadas em sacos plásticos e armazenadas em ambiente controlado $\left(18{ }^{\circ} \mathrm{C}\right.$ e $50 \%$ de umidade relativa) até o início do experimento.

$\mathrm{O}$ delineamento estatístico utilizado foi o inteiramente casualizado, com sete tratamentos (concentrações salinas) e quatro repetições, em que a parcela foi representada por uma bandeja contendo 25 sementes. As concentrações salinas foram obtidas através da adição de $\mathrm{NaCl}$ em água de forma que a solução fosse calibrada para as condutividades elétricas (C.E.) $\mathrm{T} 2=1,5 ; \mathrm{T} 3=2,5 ; \mathrm{T} 4=3,5 ; \mathrm{T} 5=$ 4,$5 ; \mathrm{T} 6=5,5$ e $\mathrm{T} 7=6,5 \mathrm{dS} \mathrm{m}-1$, que juntamente com a testemunha (água de poço, $\mathrm{T} 1=0,5 \mathrm{dS} \mathrm{m}-1$ ), constituíram os tratamentos.

Inicialmente, as sementes de $P$. stipulacea foram submetidas a superação da dormência pelo método do desponte (pequeno corte na região oposta a micrópila), seguindo as recomendações de Farias et al. (2013). Em seguida, a semeadura foi realizada em bandejas de isopor de 128 células, com volume de $40 \mathrm{~cm}^{3}$, preenchidas com substrato de fibra de coco. As irrigações foram realizadas diariamente uma vez ao dia, com um volume médio de $250 \mathrm{ml}$ por parcela, aplicando a água de acordo com os níveis salinos para cada tratamento.

Para verificar o efeito da salinidade na fase de germinação, avaliou-se a percentagem de emergência, com base no número de plântulas emergidas aos 28 dias após semeadura e a velocidade de emergência, registrando-se diariamente o número de plântulas emergidas até o vigésimo oitavo dia após a semeadura (Edmond e Drapala, 1958). Considerou-se como emergidas as plântulas com cotilédones expostos.

Para quantificar o desenvolvimento inicial, aos 28 dias após a instalação do experimento, foram coletadas 10 plântulas úteis por parcela, a partir das quais se determinou: a) comprimento da parte aérea - medição da base do colo ao ápice da plântula com auxílio de régua graduada em milímetro; b) comprimento de raiz - medição da base do colo à ponta da raiz da plântula com auxílio de régua graduada em milímetro; c) diâmetro do colo mensuração realizada na base do colo das plântulas 
com uso de paquímetro digital e resultados expressos em milímetro; e d) números de folhas por planta.

Posteriormente, as plântulas foram fracionadas em parte aérea e raízes, acondicionadas em sacos de papel tipo kraft e postas para secar em estufa de circulação de ar forçado $\left(65^{\circ} \mathrm{C}\right)$ até a obtenção de massa constante, sendo posteriormente pesadas em balança de precisão $(0,0001 \mathrm{~g})$. O peso obtido por parcela foi dividido pelo número de plântulas de cada parcela, que resultou na massa seca por plântula de cada parte correspondente, e o somatório na massa seca total.

Os dados foram submetidos à análise de variância pelo teste $\mathrm{F}(\mathrm{p}<0,01$ e $\mathrm{p}<0,05)$, utilizando-se o software SISVAR 3.01® (Ferreira, 2011). Foram geradas regressões para explicar o efeito dos diferentes níveis de salinidade da água sobre a espécie.

\section{Resultados e discussão}

$\mathrm{O}$ teste $\mathrm{F}$ apontou diferença significativa $(\mathrm{p}<$ $0,01)$ para as variáveis porcentagem de emergência (E), velocidade de emergência (VE), comprimento da parte aérea (CPA), diâmetro do colo (DC), matéria seca da parte aérea (MSPA), matéria seca das raízes (MSR) e matéria seca total (MST) de plântulas de $P$. stipulacea submetidas a diferentes níveis de salinidade na água de irrigação. Por outro lado, para o comprimento de raiz (CR) não foi detectado diferença significativa (Tabela 1$)$.

Tabela 1 Análise de variância, valores de F, para as variáveis de emergência (E), velocidade de emergência (VE), comprimento da parte aérea (CPA), comprimento de raiz (CR), diâmetro do colo (DC), matéria seca da parte aérea (MSPA), matéria seca de raiz (MSR) e matéria seca total (MST) de plântulas de Piptadenia stipulacea Benth. submetidas a diferentes níveis de salinidade na água de irrigação.

\begin{tabular}{|c|c|c|c|c|c|c|c|c|c|}
\hline \multirow[b]{2}{*}{ F. V. } & \multicolumn{9}{|c|}{ Valores de F } \\
\hline & $\mathrm{E}(\%)$ & $\begin{array}{c}\mathrm{VE} \\
\text { (dias) }\end{array}$ & $\mathrm{CPA}(\mathrm{cm})$ & $\begin{array}{l}\mathrm{CR} \\
(\mathrm{cm})\end{array}$ & NF & $\begin{array}{c}\mathrm{DC} \\
(\mathrm{mm})\end{array}$ & $\begin{array}{c}\text { MSPA } \\
\text { (g/planta) }\end{array}$ & $\begin{array}{c}\text { MSR } \\
\text { (g/planta) }\end{array}$ & $\begin{array}{c}\text { MST } \\
\text { (g/planta) }\end{array}$ \\
\hline Trat & $241,7^{* *}$ & $7,64^{* *}$ & $27,47^{* *}$ & $2,09^{\mathrm{ns}}$ & $10,66^{* *}$ & $8,06^{* *}$ & $85,29^{* * *}$ & $43,55^{* *}$ & $102,4^{* *}$ \\
\hline C.V. (\%) & 8,72 & 4,32 & 7,41 & 8,56 & 6,65 & 4,76 & 7,95 & 14,95 & 7,68 \\
\hline Média & 66,21 & 5,85 & 7,77 & 4,80 & 2,91 & 1,23 & 0,03 & 0,007 & 0,04 \\
\hline
\end{tabular}

** significativo a $1 \%$, n.s. - não significativo a $5 \%$ de probabilidade, pelo teste $\mathrm{F}$.

Os resultados obtidos para comprimento da raiz podem estar atribuídos ao fato de as plântulas terem sido cultivadas em bandejas de células, onde não houve espaço adequado para o desenvolvimento do sistema radicular, principalmente, no tocante a profundidade. Esse fato, também, foi constatado por Nogueira et al. (2012b) em estudo com plântulas Mimosa caesalpiniifolia Benth.

A porcentagem de emergência decresceu à medida que a salinidade da água de irrigação aumentou. Quando irrigada com água salina de 0,5 $\mathrm{dS} \mathrm{m} \mathrm{m}^{-1}$, a emergência de plântulas foi de $80 \%$, tolerando bem o incremento da salinidade até 4,5 dS $\mathrm{m}^{-1}$, a partir desse nível, houve redução acentuada da emergência de plântulas, com valor inferior a $40 \%$ quando irrigadas com água salina de $6,5 \mathrm{dS} \mathrm{m}^{-1}$
(Figura 1A). O acúmulo de sais no solo provoca uma queda no seu potencial hídrico, assim mesmo que a germinação ocorra, o baixo potencial dificulta a absorção de água pelas raízes das plântulas, o que prejudica no seu estabelecimento, fazendo com que as sementes que emitiram radícula não consigam se desenvolver, induzindo, além da redução na germinação, o aumento na formação de plântulas anormais e sementes mortas, como evidenciado por Nogueira et al. (2018) em estudo da germinação de Mimosa ophthalmocentra em laboratório, em que observaram uma redução acentuada na porcentagem de plântulas normais a partir de $12 \mathrm{dS} \mathrm{m} \mathrm{m}^{-1}$ nas temperaturas constantes de 20,25 e $30^{\circ} \mathrm{c}$ e alternada de $20-30{ }^{\circ} \mathrm{c}$. 

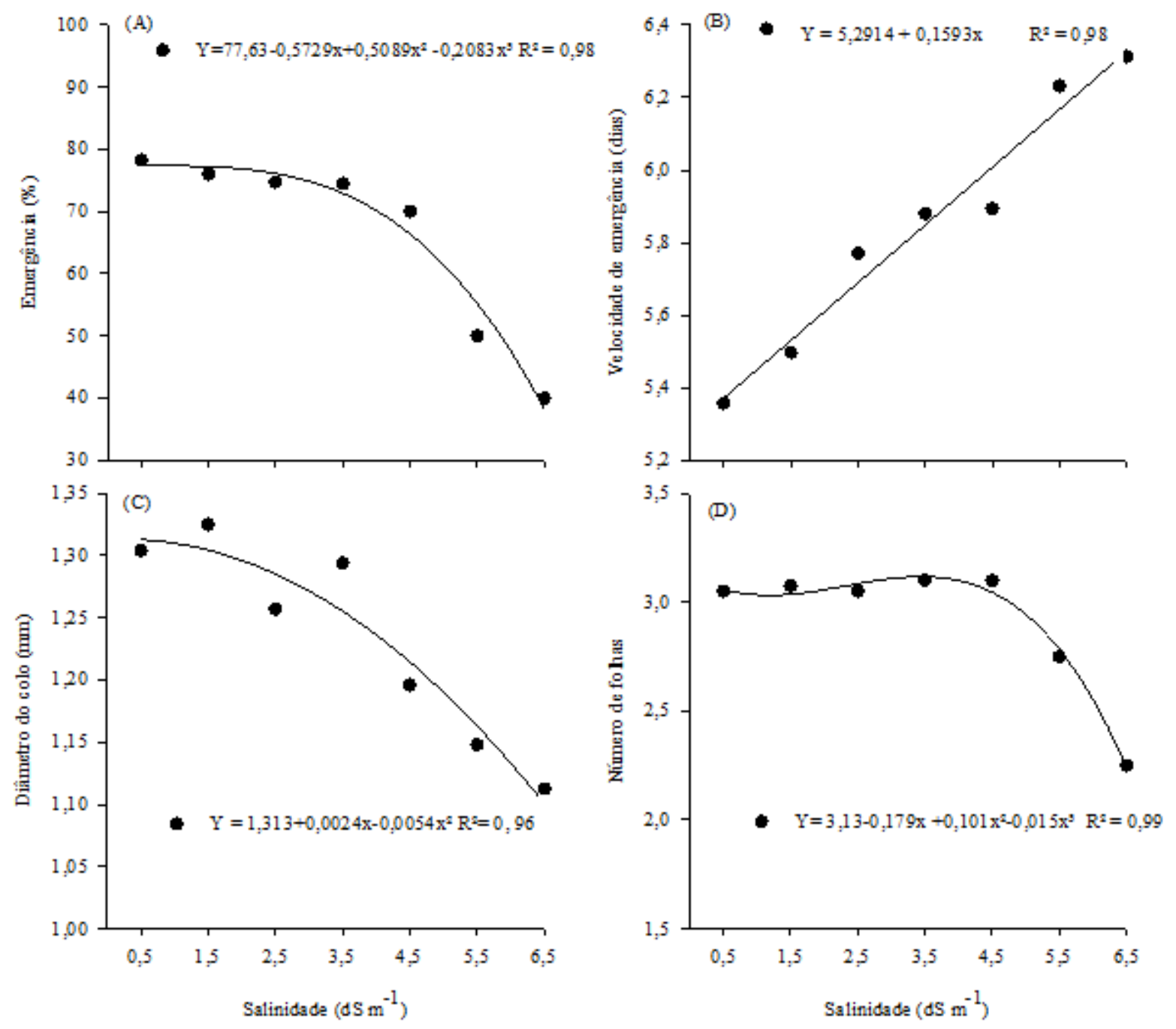

Figura 1. Emergência (A), velocidade de emergência (B), diâmetro do colo (C), número de folhas (D) por plântulas de Piptadenia stipulacea Benth. submetidas a diferentes níveis de salinidade na água de irrigação.

O aumento da concentração salina, consequentente aumento da concentração de $\mathrm{NaCl}$, no substrato, também afetou a emergência $\mathrm{e}$ desenvolvimento inicial de sementes de Libidibia férrea (Freitas et al., 2010), com redução da emergência de forma proporcional ao aumento dos níveis de salinidade da água de irrigação, o que foi mais evidente a partir da concentração de $3,0 \mathrm{dS} \mathrm{m}$ m$^{-}$ 1. Já Nogueira et al. (2012a), em trabalho realizado com Delonix regia, a porcentagem de emergência máxima de $74 \%$ foi obtida utilizaram água de irrigação com $0,5 \mathrm{dS} \mathrm{m} \mathrm{m}^{-1}$, ocorrendo redução progressiva de emergência a partir do nível de salinidade $1,5 \mathrm{dS} \mathrm{m}^{-1}$.

A velocidade de emergência apresentou comportamento linear crescente, com os menores valores obtidos para a menor salinidade $\left(0,5 \mathrm{dS} \mathrm{m}^{-1}\right)$ e os maiores verificados no nível de $6,5 \mathrm{dS} \mathrm{m}^{-1}$.
Verificou-se que quando submetidas a estresse salino, as sementes de $P$. stipulacea demoraram cerca de um dia a mais (6,3 dias) para germinar, em relação a testemunha (5,3 dias) (Figura 1B). Esse fato pode ser explicado devido ao aumento da concentração de sais no substrato ter provocado uma redução no potencial hídrico, resultando em menor capacidade de absorção de água pelas sementes, o que em geral influência a capacidade germinativa e a velocidade de sua ocorrência (Andréo-Souza et al., 2010; Martins et al., 2014).

De forma semelhante ao verificado para a porcentagem de emergência, o diâmetro do colo apresentou valores decrescentes à medida que a salinidade da água de irrigação aumentou. Quando irrigadas com água de $0,5 \mathrm{dS} \mathrm{m}^{-1} \mathrm{o}$ diâmetro do colo foi de $1,30 \mathrm{~mm}$, tolerando o incremento da salinidade até $3,5 \mathrm{dS} \mathrm{m} \mathrm{m}^{-1}$ e a partir desta concentração houve 
uma queda acentuada, chegando ao diâmetro de 1,10 mm quando as plântulas foram irrigadas com água salina de $6,5 \mathrm{dS} \mathrm{m}^{-1}$ (Figura 1C). Com isso, verificase que plantas expostas a maior salinidade, resultam em menor desenvolvimento.

Para o número de folhas, $P$. stipulacea mostrou-se tolerante a salinidade até $4,5 \mathrm{dS} \mathrm{m}{ }^{-1}$, com média de três folhas por plântula. Com o aumento da salinidade, houve redução do número de folhas, resultando em duas folhas médias por plântula quando estas foram irrigadas com água de concentração salina de $6,5 \mathrm{dS} \mathrm{m}^{-1}$ (Figura 1D). O que se deve ao fato das sementes serem sensíveis à salinidade e, quando semeadas em soluções salinas, verifica-se inicialmente a diminuição na absorção de água, reduzindo a taxa de desenvolvimento, acarretando em folhas menores e em menor número, diminuindo a sua superfície transpirante (TESTER; DAVENPORT, 2003).

O maior comprimento da parte área $(9,8 \mathrm{~cm})$ foi obtido quando as plântulas foram irrigadas com a

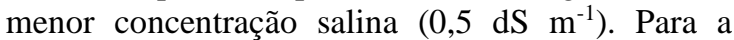
concentração de $1,5 \mathrm{dS} \mathrm{m}^{-1}$ houve pequena redução em relação a de $0,5 \mathrm{dS} \mathrm{m^{-1 }}$, mantendo-se estável até a concentração de $3,5 \mathrm{dS} \mathrm{m} \mathrm{m}^{-1}$. As plântulas que forram irrigadas com água salina de $6,5 \mathrm{dS} \mathrm{m} \mathrm{m}^{-1}$ sofreram redução de, aproximadamente, $50 \%$ do comprimento da parte aérea em comparação as que foram irrigadas com a água de $0,5 \mathrm{dS} \mathrm{m} \mathrm{m}^{-1}$, atingindo valores médios de $5 \mathrm{~cm}$ (Figura $2 \mathrm{~A}$ ).
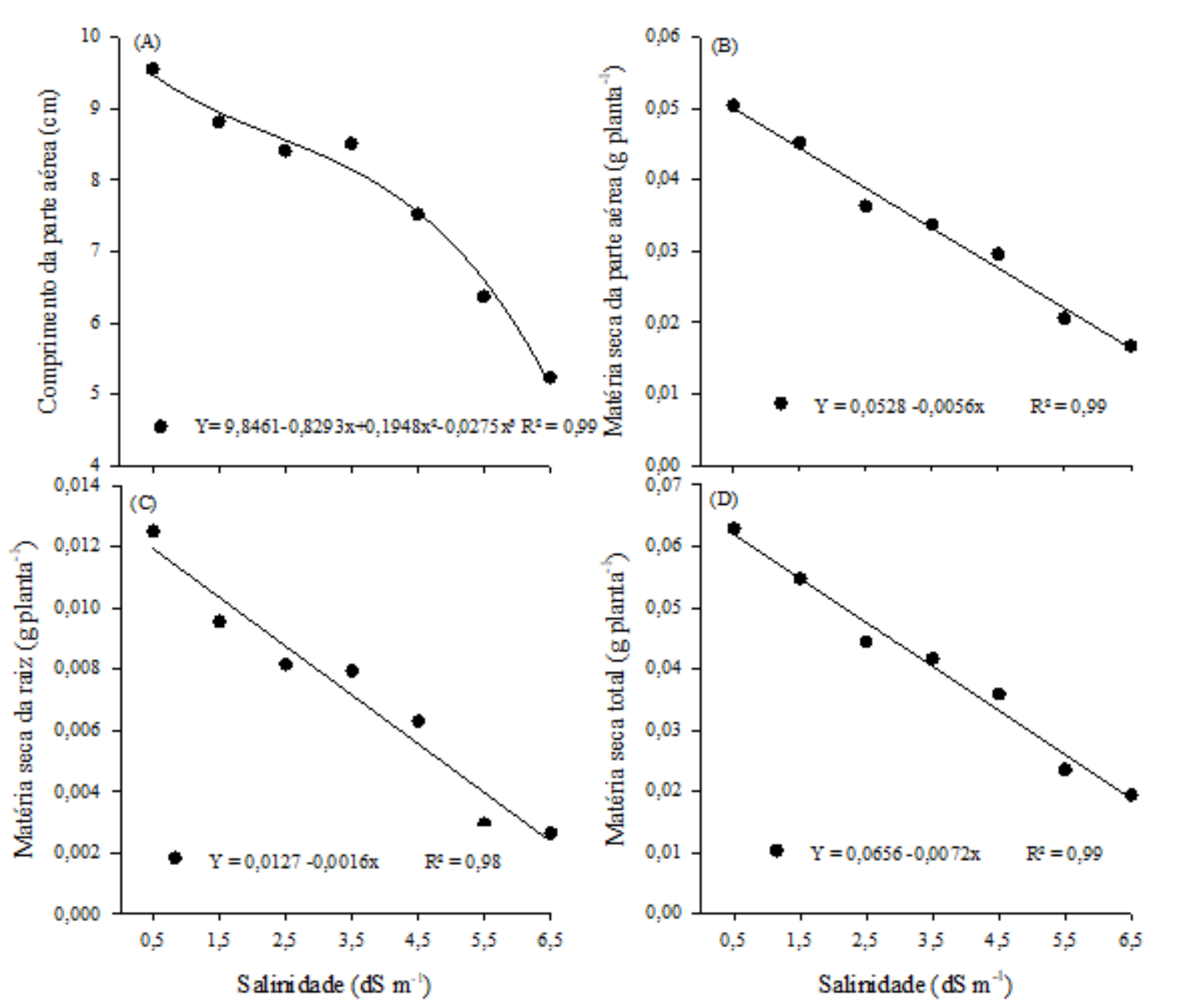

Figura 2. Comprimento da parte aérea (A), matéria seca da parte aérea (B), matéria seca da raiz (C) e matéria seca total (D) de plântulas de Piptadenia stipulacea Benth. submetidas a diferentes níveis de salinidade na água de irrigação.

Redução do comprimento parte área deve-se ao fato de o primeiro efeito mensurável do estresse hídrico/salino ser a diminuição no crescimento, causada pela redução da expansão celular ocasionada pela seca fisiológica produzida e ao efeito tóxico, resultante da concentração de íons no protoplasma (Taiz e Zeiger, 2013). Esses resultados estão de acordo com os verificados com plântulas de L. ferrea e D. regia, em trabalhos com níveis de salinidade da água de irrigação conduzidos por Freitas et al. (2010) e Nogueira et al. (2012a), respectivamente, sofreram diminuição da altura à 
medida que os níveis de salinidade aumentaram, havendo menor desenvolvimento nas plântulas submetidas a concentrações superiores a $3,0 \mathrm{dS} \mathrm{m} \mathrm{m}^{-1}$, comportando-se de forma semelhante à espécie em estudo, resultado, também, corroborado por Leal et al., (2019) com plântulas de C. leprosum. Mesmo com algumas espécies apresentando boa tolerância à salinidade (halófitas), é consenso entre os autores que as soluções salinas sempre vão causar redução no crescimento, mesmo que seja mínima, em relação as plântulas irrigadas com água normal (Leal et al., 2015).

As massas secas da parte aérea, de raiz e total apresentaram comportamentos semelhantes, linear decrescente (Figura 2B, 2C e 2D). À medida que os níveis de salinidade aumentaram, houve progressiva redução na massa seca das partes. Resultados semelhantes aos verificados por Leal et al. (2015), trabalhando com soluções salinas entre 0 e $5,5 \mathrm{dS} \mathrm{m}^{-}$ ${ }^{1}$ em casa de vegetação, verificaram que o acúmulo de matéria seca em $M$. ophthalmocentra foi reduzido, com um leve aumento inicial até $1,5 \mathrm{dSm}^{-}$ ${ }^{1}$, com o aumento da salinidade da água de irrigação; Silva et al. (2005), que observaram redução de $63,40 \%$ da massa seca de parte aérea de plântulas de Cnidosculus phyllacanthus entre o menor e o maior nível de salinidade estudado $\left(1,0\right.$ e $\left.6,0 \mathrm{dS} \mathrm{m}^{-1}\right)$ e Nogueira et al. (2012a) que verificaram redução de $62,84 \%$ da massa seca da parte aérea de plântulas de D. regia.

Embora não tenha ocorrido diferenças significativas entre os tratamentos para o comprimento de raiz, houve diferença para a massa seca das raízes, indicando que embora o comprimento das raízes tenha sido limitado pela célula da bandeja, o desenvolvimento de raízes secundárias foi maior em condições de ausência de estresse salino. Da mesma forma, Oliveira et al. (2009) com plântulas de Moringa oleifera Lam., irrigadas com soluções salinas de $\mathrm{NaCl}$ entre 0 e 5,0 dS $\mathrm{m}^{-1}$, em ambiente de casa de vegetação, verificaram que os acúmulos de matéria seca nessas plântulas foram reduzidos e estatisticamente diferentes, quando o nível de salinidade da água de irrigação foi aumentado.

\section{Conclusões}

P. stipulacea possui tolerância moderada a salinidade, desenvolvendo-se em salinidades de 4,5 $\mathrm{dSm}^{-1}$ sem que haja perdas significativas de germinação e número de folhas

A irrigação com água salina afeta de forma negativa as plântulas de $P$. stipulacea, comprometendo o desenvolvimento, o acúmulo de massa seca e o crescimento da parte aérea.

\section{Referências}

Andréo-souza, Y, Pereira, AL, Silva, FFS, Riebeiroreis, RC, Evangelista, MRV, CASTRO, RD, Dantas, BF (2010) Efeito da salinidade na germinação de sementes e no crescimento inicial de mudas de pinhão-manso. Revista Brasileira de Sementes, 32 (2): 83-92. http://dx.doi.org/10.1590/S010131222010000200010

Barreto, HBF. Freitas, RMO, Oliveira, LAA, Araujo, JAM, Costa, EM (2010) Efeito da irrigação com água salina na germinação de sementes de sabiá (Mimosa caesalpiniifolia Benth.). Revista Verde, 5 (3):

125-130.

https://www.gvaa.com.br/revista/index.php/RVAD S/article/viewFile/314/314

Edmond, JB, Drapala, WJ (1958) The effects of temperature, sandand soil, and acetone on germination of okra seeds. Proceedings of American Society of Horticultural Science, 71: 428434.http://www.scielo.br/scielo.php?script=sci_nlin ks\&ref $=000090 \&$ pid $=$ S0101$3122200500010000800011 \& \operatorname{lng}=\mathrm{pt}$

Farias, RMF, Freitas, RMO, Nogueira, NW, DombroskI, JLD (2015) Superação de dormência em sementes de Jurema-branca (Piptadenia stipulacea). Revista de Ciências Agrárias, 56 (2):160-165. http://dx.doi.org/10.4322/rca.2013.024

Ferreira, DF (2011) Sisvar: a computer statistical analysis system. Ciência e Agrotecnologia, 35 (6). 1039-1042. http://dx.doi.org/10.1590/S141370542011000600001

Freitas, RMO, Nogueira, NW, Oliveira, FN, Costa, EM, Ribeiro, MCC (2010) Efeito da irrigação com água salina na emergência e crescimento inicial de plântulas de Jucá. Revista Caatinga, 23 (3): 54-58. https://periodicos.ufersa.edu.br/index.php/caatinga/ article/view/1627/4592

Guimarães, IP, Oliveira, FN, Vieira, FER, Torres, SB (2013) Efeito da salinidade da água de irrigação na emergência e crescimento inicial de plântulas de mulungu. Revista Brasileira de Ciências Agrárias, 8 (1):

137-142. https://dx.doi.org/10.5039/agraria.v8i1a2360

Holanda, JS, Amorim, JRA, Neto, MF, Holanda, AC (2010) Qualidade da água para irrigação. In: Gheyi, RH, Dias, NS, Lacerda, CF, (Eds.) - Manejo da salinidade na agricultura: Estudos básicos e aplicados. Fortaleza, INCT Sal. 472p.

Leal, CCP, Dantas, NBL, Torres, SB, Vale, AAM, Freitas, RMO (2019) Initial development of Combretum leprosum Mart. seedlings irrigated with saline water of different cationic natures. Revista Ciência Agronômica, $50 \quad$ (2): 300-306. https://dx.doi.org/10.5935/1806-6690.20190035 
Leal, CCP, Torres, SB, Nogueira, NW, Freitas, RMO, Farias, RM (2015) Emergence and early development of seedlings of Mimosa ophthalmocentra Mart. ex Benth. irrigated with brackish water. Bioscience Journal, 31 (3): 759-766. http://www.seer.ufu.br/index.php/biosciencejournal /article/view/26082/16461

Lima, MGS, Lopes, NF, Moraes, DM, Abreu, CM (2005) Qualidade fisiológica de sementes de arroz submetidas a estresse salino. Revista Brasileira de Sementes, 27 (1): 54-61. https://dx.doi.org/ 10.1590/S0101-31222005000100007

Maia, NG (2012) Caatinga: árvores e arbustos e suas utilidades. 2 ed. São Paulo: D \& Z Computação Gráfica e Editora, 413p.

Martins, CC, Pereira, MRR, Lopes, MTG (2014). Germinação de sementes de eucalipto sob estresse hídrico e salino. Bioscience Journal, 30: 318-329. http://www.seer.ufu.br/index.php/biosciencejournal /article/view/18058/14543

Matias, JR, Torres, SB, Freire, JNT, Alencar, SS, Dantas, BF (2018) Germinação de sementes de Cenostigma pyramidale sob diferentes temperaturas e salinidades. Informativo Abrates, 18 (1). http://www.alice.cnptia.embrapa.br/alice/handle/do c/1109073

Nogueira, NW, Lima, JSS, Freitas, RMO, Ribeiro, MCC, Leal, CCP, Pinto, JRS (2012a ) Efeito da salinidade na emergência e crescimento inicial de plântulas de flamboyant. Revista brasileira de Sementes, $\quad 34 \quad$ (3): $\quad 466-472$. http://dx.doi.org/10.1590/S0101-

31222012000300014.

Nogueira, NW, Ribeiro, MCC, Freitas, RMO, Matuoka, MY, Sousa, VFL (2012b) Emergência e desenvolvimento inicial de plântulas Mimosa caesalpiniifolia Benth. em função de diferentes substratos. Revista Agroambiente, 6 (1): 17-24. http://dx.doi.org/10.18227/1982-

8470ragro.v6i1.695

Nogueira, NW, Torres, SB, Freitas, RMO, Santos, PCS, Sá, FVS, Leite, MS (2018) Salt stress and temperatures on the germination and initial growth of 'jurema-de-embira' (Mimosa ophthalmocentra) seedlings. Revista Brasileira de Engenharia Agrícola e Ambiental, $22 \quad$ (4): 273-278. https://doi.org/10.1590/18071929/agriambi.v22n4p273-278

Oliveira, FRA, Oliveira, FA, Guimarães, IP, Medeiros, JF, Oliveira, MKT, Freitas, AVL, Medeiros, MA (2009) Emergência de plântulas de moringa irrigada com água de diferentes níveis de salinidade. Bioscience Journal, 25 (5): 66-74. http://www.seer.ufu.br/index.php/biosciencejournal /article/view/6987/4630

Perez, SCJGA, Jardim, MM (2005) Viabilidade e vigor de sementes de paineira após armazenamento, condicionamento e estresses salino e térmico. Pesquisa Agropecuária Brasileira, 40 (6): 587-593. http://dx.doi.org/10.1590/S0100204X2005000600009

Ribeiro, MCC, Barros, NMS, Barros Júnior, AP, Silveira, LM (2008) Tolerância do sabiá (Mimosa caesalpiniaefolia Benth.) à salinidade durante a germinação e o desenvolvimento de plântulas. Revista Caatinga, 21 (5): 123-126. https://periodicos.ufersa.edu.br/index.php/caatinga/ article/view/875/486

Silva, MBR, Batista, RC, Lima, VLA, Barbosa, EM, Barbosa MFN (2005) Crescimento de plantas jovens da espécie florestal favela (Cnidosculus phyllacanthus Pax \& K. Hoffmem) em diferentes níveis de salinidade da água. Revista de Biologia e Ciências da Terra, 5 (2). http://joaootavio.com.br/bioterra/workspace/upload s/artigos/favela-5182deea7c904.pdf

Taiz, L.; Zeiger, E (2013) Fisiologia vegetal. 5 eds. Porto Alegre: ARTMED, 918p.

Tester, M, Davenport, R (2003) $\mathrm{Na}^{+}$tolerance and $\mathrm{Na}^{+}$transport in higher plants. Annals of Botany, 91 (3): 503-527. https://doi.org/10.1093/aob/mcg058 